\title{
Toxoplasma gondii and Psychopathology: Latent Infection Is Associated with Interpersonal Sensitivity, Psychoticism, and Higher Testosterone Levels in Men, but Not in Women
}

\author{
Javier I. Borráz-León ${ }^{1,2,3}$ - Markus J. Rantala ${ }^{1}$ • Severi Luoto ${ }^{4,5}$ • \\ Indrikis Krams ${ }^{6,7,8}$. Jorge Contreras-Garduño ${ }^{3}$ - Ana Lilia Cerda-Molina ${ }^{2}$. \\ Tatjana Krama ${ }^{9}$
}

Received: 14 October 2020 / Revised: 23 December 2020 / Accepted: 28 December 2020 /

Published online: 7 January 2021

(C) The Author(s) 2021

\begin{abstract}
Objective The ability of parasites to hijack the nervous system, manipulating the host's physiology and behavior in ways that enhance the parasite's fitness while damaging host fitness, is a topic of ongoing research interest in evolutionary biology, but is largely overlooked in mental health research. Nevertheless, recent evidence has shown that Toxoplasma gondii infection can change host testosterone levels and influence the development of some psychiatric disorders. Here, we tested this hypothesis in a mixed sample of 213 non-clinical subjects.

Methods Participants $\left(n_{\text {males }}=108, n_{\text {females }}=105\right.$ ) provided $5 \mathrm{ml}$ of blood to quantify testosterone levels and Toxoplasma gondii antibodies. The Symptom Checklist-90Revised was used to assess psychopathological symptoms.

Results The results showed that Toxoplasma-infected men had higher testosterone levels and scored higher in Interpersonal Sensitivity and Psychoticism symptoms than non-infected men. Toxoplasma-infected women did not differ from control women.

Conclusions Framed in an evolutionary framework, the findings suggest that the elevated testosterone levels and the expression of psychopathological symptoms can be seen as the result of the manipulation exerted by Toxoplasma gondii either to reach its definitive host or to increase its spread. Future research can benefit from integrating insights from evolutionary biology and parasite-host interactions with physiology, immunology, and mental health to develop a better understanding of mental health etiology.
\end{abstract}

Keywords Toxoplasmosis $\cdot$ Parasites $\cdot$ Steroid hormones $\cdot$ Mental health $\cdot$ Evolutionary theory

Javier I. Borráz-León

jibole@utu.fi; borraz@comunidad.unam.mx

Extended author information available on the last page of the article 


\section{Introduction}

Research and diagnostic criteria of mental disorders are based on the presence of specific symptoms measured by tools such as The Diagnostic and Statistical Manual of Mental Disorders, Fifth Edition (DSM-V) or the 10th revision of the International Statistical Classification of Diseases and Related Health Problems (ICD-10) (Rantala et al. 2018). However, an integrative approach taking into account hormonal profiles, life history traits, or even the evaluation of microbiota and parasites could effectively improve the diagnosis and treatment of psychopathologies (Del Giudice and Ellis 2016; Del Giudice 2019; Rantala et al. 2019).

Psychopathology is defined according to factors such as functional impairment, suffering, irrationality, harmful dysfunction, loss of control, as well as other abnormal psychological variables (Maddux and Winstead 2015; Cicchetti 2016). Although current understanding on the causes underlying the development of psychopathology is incomplete, complex interactions between genotype, social, and ecological factors such as traumatic experiences in early stages of life, chronic stress, poor hormonal regulation, microbiome, and even side effects of some parasites are all implicated in the development of psychopathology (Del Giudice and Ellis 2016; Manning 2019; Rantala et al. 2019).

A key hormone closely related to psychopathologies is testosterone (Figueira and Ouakinin 2010). Testosterone is the main sex steroid hormone responsible for the development of primary and secondary sexual characteristics in males (Eisenegger et al. 2011). Previous literature has shown not only relationships between testosterone levels and the expression of personality traits in both sexes (Giammanco et al. 2005; Cobey et al. 2015; Costa et al. 2015; Borráz-León et al. 2018, see also Luoto et al. 2019; Luoto 2020), but also associations between abnormally high or low testosterone concentration and the development of some mental disorders such as depression, anxiety, and bipolar disorder (Booth et al. 1999; Khera 2013; Barch et al. 2020).

Another important factor related to psychopathologies is the parasite Toxoplasma gondii (T. gondii), an intracellular and neurotropic parasite with domestic cat and other felides as definitive hosts, and with a broad spectrum of intermediate warm-blood animal hosts, including human beings (Flegr 2007). It has been estimated that around $30 \%$ of the global population could be infected with $T$. gondii, and that the main route of infection is through the ingestion of contaminated food or water that contains tissue cysts (Montoya and Liesenfeld 2004). T. gondii infection - known as toxoplasmosiscauses mild disease and usually turns into life-long latent toxoplasmosis, being clinically asymptomatic in immunocompetent subjects (Roberts et al. 2001). Despite its apparent null effect on general health, latent toxoplasmosis may impose changes in behavior and personality of infected subjects (Del Giudice 2019). For example, infected men are more expedient, suspicious, jealous, and dogmatic, whereas infected women are more warm-hearted, outgoing, conscientious, persistent, and moralistic than noninfected subjects (Flegr 2007).

Moreover, in recent years, latent toxoplasmosis has also been associated with the development of some mental disorders such as schizophrenia, obsessive-compulsive disorder, and suicidal tendencies (Torrey et al. 2006; Flegr and Horáček 2019; Torrey and Yolken 2019), and there is evidence that testosterone feedback regulation could also be modulated by $T$. gondii (Flegr et al. 2008; Del Giudice 2019). For example, T. gondii invades testes in male rodents and increases testosterone production (Del 
Giudice 2019). Interestingly, some behavioral and cognitive changes have also been observed in intermediate hosts which could increase the risk of being caught by felines (Webster 2001), such as Toxoplasma-infected chimpanzees' increased attraction to leopard urine (Poirotte et al. 2016). This has been interpreted as an evolutionary adaptation of the parasite to complete its life-cycle within its definitive host (Poirotte et al. 2016; Brüne 2019). However, this hypothesis is just beginning to be empirically explored in humans. To add relevant information to the existing body of knowledge, the aim of the current research was to compare psychopathological symptoms and testosterone levels in subjects with positive latent toxoplasmosis vs. non-infected subjects in a sample of young adults, including both men and women.

Based on previous research (Brüne 2019; Del Giudice 2019), we predicted that latent toxoplasmosis increases testosterone levels and the incidence of mental disorders. Hence, infected subjects should have higher psychopathological symptoms and higher testosterone levels than non-infected subjects.

\section{Methods}

\section{Participants}

A sample of 240 healthy college students (115 men and 125 women) was recruited by personal and online invitations at the National Autonomous University of Mexico, Morelia and Mexico City, Mexico. The inclusion criteria for both sexes were the following: not having chronic diseases (e.g., diabetes or cancer), and not being subjected to hormonal therapy or psychiatric medication. In addition to these criteria, it was requested that women have regular menstrual cycles (so that a difference between consecutive cycle lengths was usually not longer than \pm five days), as well as not being pregnant, breastfeeding, or taking hormonal contraception for at least three months prior to the study (Richards et al. 2018). From our original sample, thirteen participants were excluded because of incomplete questionnaires, seven because of reports of previous psychiatric diagnoses and medication, and seven because of hemolyzed blood samples. Thus, the final sample was composed of 213 subjects (108 men and 105 women). The mean age was 22.92 years $(\mathrm{SD}=4.53)$ for men and $21.15(\mathrm{SD}=3.05)$ for women.

Following the approval of the appropriate local ethics committee, participants received detailed information about the aim and procedure of the study, signed a letter of informed consent, and answered a general demographic questionnaire (i.e., body mass, height, and age). We collected $5 \mathrm{ml}$ of blood from all participants between 9:00 and 13:00 $\mathrm{h}$ for serological testing. To control for hormonal fluctuations across the menstrual cycle of women, we applied the questionnaires and took the blood samples during the peri-ovulatory phase of the menstrual cycle (between day 12 and day 16) (Welling et al. 2007; Marcinkowska et al. 2019). The participants received their hormonal, immunological, and psychological results as compensation for taking part in the research.

\section{Symptom Checklist 90}

To measure symptoms of general psychopathology, we used the Spanish version of the Symptom Checklist-90-Revised (SCL-90-R) (Derogatis and Unger 2010). Previous 
studies have shown a moderate-to-high validity and reliability of the Spanish version in Mexican samples (Cronbach's $\alpha=0.80$, Cruz Fuentes et al. 2005; Lara et al. 2015). SCL-90-R is a 90-item self-report symptom inventory that assesses psychological distress (e.g., headaches, trouble remembering things, trembling, suddenly scared for no reason, feeling blue, trouble falling asleep, etc.) in relation to nine primary symptom dimensions and three summary scores (termed 'global scores'), using a five-point Likert-type scale ( $1=$ not at all; $5=$ extremely). In this research, we used the nine primary dimensions labeled as Somatization $(\alpha=0.81)$, Obsessive-Compulsive $(\alpha=$ $0.80)$, Interpersonal Sensitivity ( $\alpha=0.83)$, Depression $(\alpha=0.79)$, Anxiety $(\alpha=0.81)$, Hostility $(\alpha=0.74)$, Phobic Anxiety $(\alpha=0.79)$, Paranoid Ideation $(\alpha=0.80)$, and Psychoticism $(\alpha=0.81)$.

\section{Testosterone Quantification}

Immediately after collection, blood samples were centrifuged at $3000 \mathrm{rpm}$ for $10 \mathrm{~min}$ at room temperature $\left(\approx 20^{\circ} \mathrm{C}\right)$. From these, $1.5 \mathrm{ml}$ of serum was collected in Eppendorf tubes and frozen until hormonal analyses were conducted. No special pretreatment of samples was necessary. Testosterone for each sample was determined from the average of two duplicates using commercial ELISA kits (Testosterone, $611 \mathrm{CH}$, International Immuno-Diagnostics, CA, USA). The concentrations of testosterone were reported in nanograms per milliliter $(\mathrm{ng} / \mathrm{ml})$. Within-assay coefficients of variability of standards and unknown samples averaged less than $5 \%$. The sensitivity of the kits was from 0.1 to $18 \mathrm{ng} / \mathrm{ml}$.

\section{Immunological Tests for Toxoplasmosis}

Specific anti-Toxoplasma IgG were determined by commercial ELISA kits (Toxoplasma IgG, IIDE-2041, International Immuno-Diagnostics, CA, USA). Following the information provided by the kits, samples $<0.9 \mathrm{UI} / \mathrm{ml}$ were considered as latent toxoplasmosis negative, samples from 0.9 to $0.99 \mathrm{UI} / \mathrm{ml}$ as suspicious, and samples $>1.0 \mathrm{UI} / \mathrm{ml}$ as latent toxoplasmosis positive. If the result of a sample looked suspicious, it was measured once again. All serum samples were run in duplicates and averaged across the two tests.

The serologic test for the detection of $\mathrm{IgG}$ antibodies is commonly associated with latent toxoplasmosis infection in immunocompetent subjects (e.g., Cook et al. 2015). For this study, the subjects with positive IgG values were considered as latent toxoplasmosis positive (experimental group) whereas negative values of IgG were considered as non-infected subjects (control group).

\section{Statistical Analyses}

Since our data did not meet the normality criteria after being log-transformed (Shapiro-Wilk Test: $p<0.05$ in all cases), we ran non-parametric tests. Independent Mann-Whitney $U$ tests were used to look for potential sex differences among the studied variables. A Generalized Linear Model (GLM) was performed to study the relations between testosterone levels as a dependent variable and IgG levels as an independent variable (with serum collection time, 
sex, age, and BMI as covariates). To identify potential differences between latent Toxoplasma-infected vs. non-infected subjects regarding testosterone levels and each one of the psychopathological symptoms, a series of independent Mann-Whitney $U$ tests were carried out for the whole sample and for the male and the female samples separately. The threshold for statistical significance was set at $p \leq 0.05$. The data were analyzed using SPSS version 25 (SPSS Inc., Chicago, IL, USA).

\section{Ethical Note}

The authors assert that all procedures contributing to this work comply with the ethical standards of the relevant national and institutional committees on human experimentation and with the Helsinki Declaration of 1975, as revised in 2008.

\section{Results}

\section{Sex Differences}

The following sex differences were found in the sample: the men were older, had higher body mass index, and higher testosterone levels than women, whereas women reported higher scores of Somatization, Depression, Phobic Anxiety, and a tendency to higher Anxiety than men (Table 1).

Table 1 Sex differences in age, body mass index, testosterone levels, and psychopathological symptoms $(N=$ 213)

\begin{tabular}{lcccccc}
\hline & Men $(n=105)$ & Women $(n=108)$ & & & \\
\cline { 3 - 6 } & Mean $(S D)$ & Mean $(S D)$ & $p$ & Hedges' $g$ & 95\% CI for Hedges' $g$ \\
\cline { 3 - 6 } & & & & Lower & Upper \\
\hline Age & & & & & & \\
BMI & $22.92(4.53)$ & $21.15(3.05)$ & $<0.001$ & 0.45 & 0.18 & 0.72 \\
Testosterone & $24.63(4.11)$ & $23.17(3.60)$ & 0.009 & 0.37 & 0.10 & 0.64 \\
Somatization & $5.02(3.11)$ & $1.11(1.60)$ & $<0.001$ & 1.56 & 1.26 & 1.88 \\
Obsessive-Compulsive & $1.32(0.74)$ & $1.40(0.89)$ & 0.616 & -0.09 & -0.36 & 0.17 \\
Interpersonal Sensitivity & $0.91(0.73)$ & $1.08(0.87)$ & 0.215 & -0.21 & -0.48 & 0.05 \\
Depression & $0.92(0.69)$ & $1.27(0.92)$ & 0.009 & -0.42 & -0.70 & -0.15 \\
Anxiety & $0.78(0.60)$ & $1.00(0.74)$ & 0.069 & -0.32 & -0.59 & 0.05 \\
Hostility & $0.85(0.82)$ & $0.76(0.76)$ & 0.458 & 0.11 & -0.15 & 0.38 \\
Phobic Anxiety & $0.39(0.44)$ & $0.61(0.66)$ & 0.036 & -0.39 & -0.66 & -0.12 \\
Paranoid Ideation & $0.91(0.67)$ & $0.93(0.80)$ & 0.693 & 0.02 & -0.29 & 0.24 \\
Psychoticism & $0.65(0.56)$ & $0.69(0.65)$ & 0.917 & -0.06 & -0.33 & 0.20 \\
\hline
\end{tabular}




\section{Positive Latent Toxoplasmosis in Men and Women}

For the whole sample the results were as follows: 35 subjects $(16.40 \%)$ met the inclusion criterion (i.e., Toxoplasma IgG positive) whereas $178(83.60 \%)$ did not. Twenty-two men (20.04\%) tested positive for Toxoplasma IgG whereas 86 (79.60\%) did not. Thirteen women (12.40\%) tested positive for Toxoplasma IgG and 92 $(87.40 \%)$ did not. No sex difference was found in the probability of being infected by $T$. gondii $\left(\chi^{2}=2.47, p=0.110\right)$.

\section{Association between Toxoplasmosis Status and Testosterone Levels}

The GLM showed that the effect of IgG and sex on testosterone levels was statistically significant (sex: $B=3.642$, Wald $=116.946, d . f .=1, p<0.001 ; \mathrm{IgG}: B=-1.852$, Wald $=17.412$, d.f. $=1, p<0.001)$. Non-significant results were found for serum collection time, age, and BMI $(B=-0.071$, Wald $=0.219$, d.f. $=1, p=0.640 ; B=0.047$, Wald $=$ 1.158 , d.f. $=1, p=0.282$; and $B=0.032$, Wald $=0.546$, d.f. $=1, p=0.460$, respectively). The relationship between testosterone and IgG levels therefore depended on sex, as shown further in the confirmatory analyses in the next section.

\section{Differences in Testosterone and Psychopathological Symptoms Concerning Toxoplasmosis Status}

In the male group only, Toxoplasma-infected subjects had higher testosterone levels, higher Interpersonal Sensitivity, and higher Psychoticism than non-infected men (Testosterone: $p<0.001$, Hedges' $g=1.24,95 \%$ CI [0.74, 1.73]; Interpersonal sensitivity: $p$ $=0.030$, Hedges' $g=0.34,95 \%$ CI $[-0.12,0.81]$; Psychoticism: $p=0.037$, Hedges' $g=$ $0.26,95 \%$ CI $[-0.20,0.73]$ ) (Figs. 1, 2, and 3, respectively). Non-significant results were found for the rest of the psychopathological symptom dimensions $(p>0.05$ in all cases, Table 2). None of the results in women reached our threshold of statistical significance $(p>0.05$ in all cases, Table 3$)$.

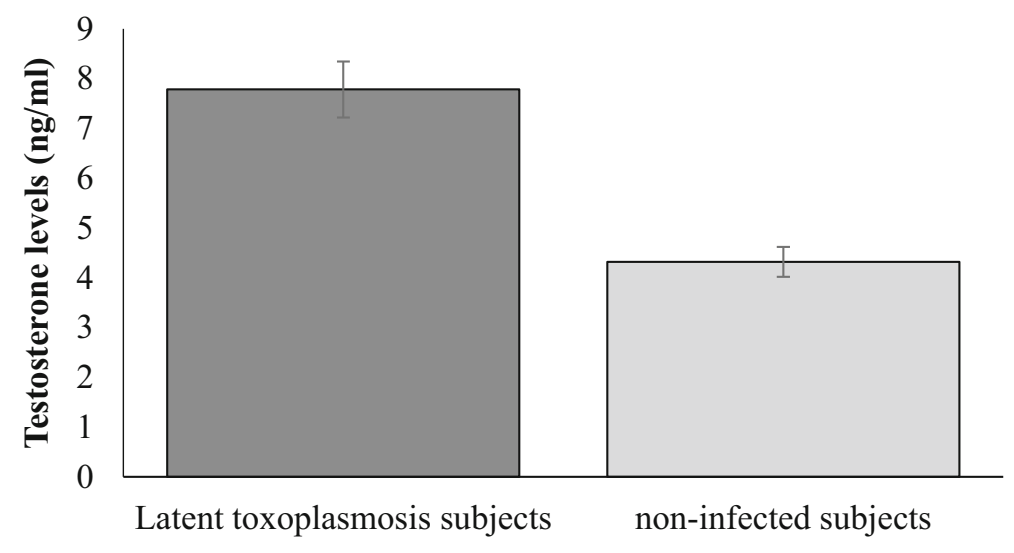

\section{Toxoplasmosis status}

Fig. 1 Toxoplasma-infected men had higher testosterone levels than non-infected subjects (Mann-Whitney U test: $p<0.001$, Hedges' $g=1.24,95 \%$ CI $[0.74,1.73]$ ) 


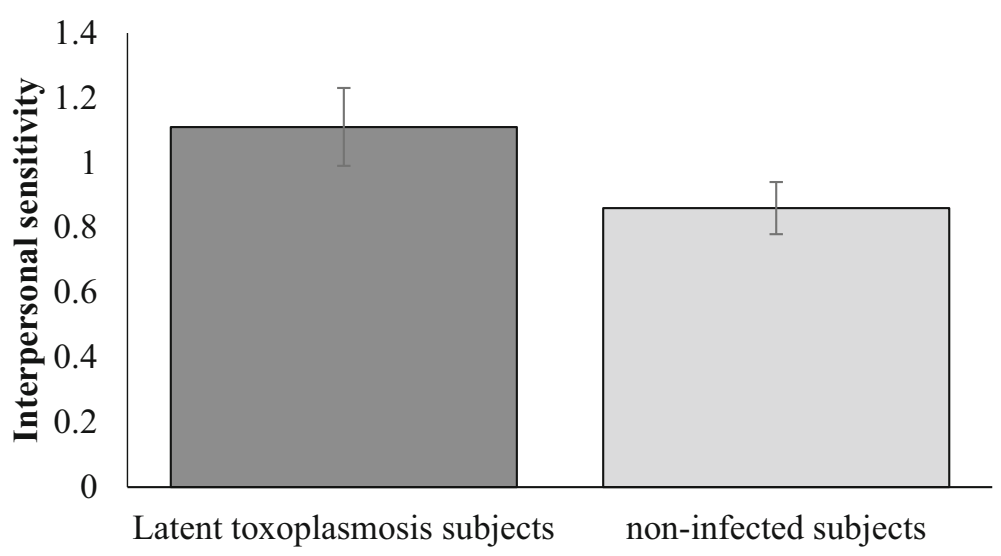

Toxoplasmosis status

Fig. 2 Toxoplasma-infected men had higher interpersonal sensitivity than non-infected subjects (MannWhitney U test: $p=0.030$, Hedges' $g=0.34,95 \%$ CI $[-0.12,0.81]$ )

\section{Discussion}

The main aim of this study was to compare differences in psychopathological symptoms and testosterone levels between positive latent toxoplasmosis vs. non-infected subjects both in men and women. The results showed that men (but not women) with positive latent toxoplasmosis had higher testosterone levels and scored higher in Interpersonal Sensitivity and Psychoticism than non-infected men.

The observed higher testosterone levels in Toxoplasma-infected men are in line with previous literature (e.g., Flegr et al. 2008; Zouei et al. 2018). Even though the proximate mechanisms by which $T$. gondii regulates the synthesis of testosterone remain unknown, it has been suggested that this parasite could enhance mRNA expression of luteinizing hormone receptor, which modulates the synthesis of testosterone in the Leydig cells of the testes (Lim et al. 2013). Moreover, Toxoplasma-

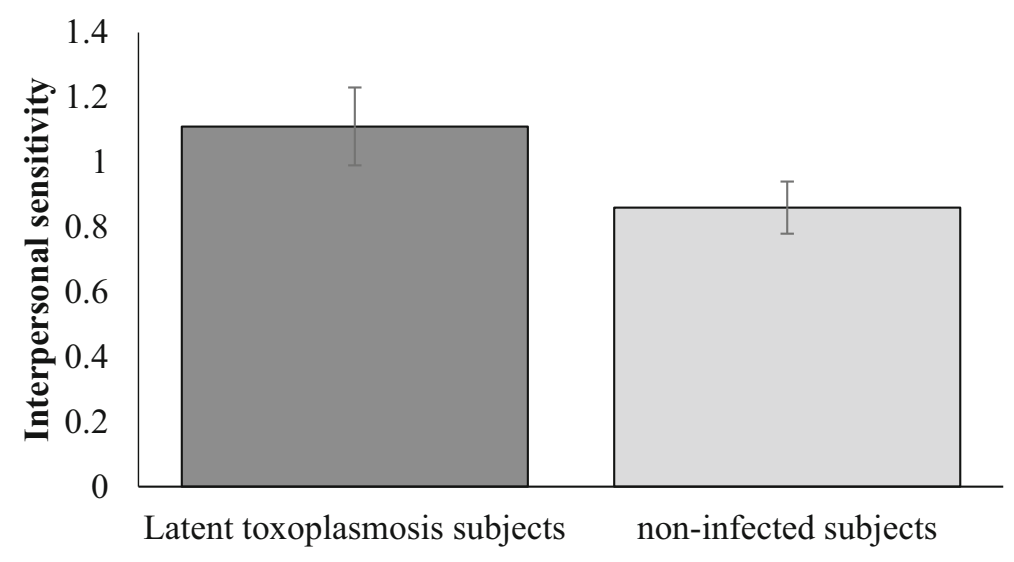

Toxoplasmosis status

Fig. 3 Toxoplasma-infected men had higher psychoticism than non-infected subjects (Mann-Whitney U test: $p=0.037$, Hedges' $g=0.26,95 \%$ CI $[-0.20,0.73]$ ) 
Table 2 Differences in testosterone and psychopathological symptoms between Toxoplasma-infected and non-infected men

\begin{tabular}{|c|c|c|c|c|c|c|}
\hline & $\begin{array}{l}\text { Toxoplasma-infected } \\
\text { men }(n=22)\end{array}$ & $\begin{array}{l}\text { Non-infected men } \\
(n=86)\end{array}$ & & & & \\
\hline & Mean $(S D)$ & Mean $(S D)$ & $p$ & Hedges' $g$ & \multicolumn{2}{|c|}{$\begin{array}{l}\text { 95\% CI for } \\
\text { Hedges' } g\end{array}$} \\
\hline & & & & & Lower & Upper \\
\hline Testosterone & $7.78(2.66)$ & $4.32(2.82)$ & $<0.001$ & 1.24 & 0.74 & 1.73 \\
\hline Somatization & $0.71(0.41)$ & $0.74(0.63)$ & 0.614 & -0.05 & -0.51 & 0.41 \\
\hline Obsessive-Compulsive & $1.43(0.63)$ & $1.29(0.76)$ & 0.394 & 0.18 & -0.27 & 0.65 \\
\hline Interpersonal Sensitivity & $1.11(0.57)$ & $0.86(0.76)$ & 0.030 & 0.34 & -0.12 & 0.81 \\
\hline Depression & $1.03(0.69)$ & $0.89(0.69)$ & 0.326 & 0.20 & -0.26 & 0.67 \\
\hline Anxiety & $0.85(0.56)$ & $0.78(0.61)$ & 0.409 & 0.11 & -0.35 & 0.58 \\
\hline Hostility & $0.88(0.82)$ & $0.84(0.83)$ & 0.791 & 0.04 & -0.42 & 0.51 \\
\hline Phobic Anxiety & $0.36(0.46)$ & $0.39(0.44)$ & 0.650 & -0.06 & -0.53 & 0.40 \\
\hline Paranoid Ideation & $1.02(0.42)$ & $0.88(0.72)$ & 0.104 & 0.21 & -0.25 & 0.68 \\
\hline Psychoticism & $0.77(0.41)$ & $0.62(0.59)$ & 0.037 & 0.26 & -0.20 & 0.73 \\
\hline
\end{tabular}

infected animals (Del Giudice 2019) and men (Szczypka et al. 1998; Hull et al. 2004) also have higher dopamine levels, probably as a response to local inflammatory processes (Flegr 2007). Thus, it is feasible to propose that $T$. gondii could change the brain architecture related to testosterone (and dopamine) regulation (e.g., the hypothalamic-pituitary-gonads axis) (Del Giudice 2019). This, in turn, would affect the expression of personality, behavior, and possibly the development of psychopathologies (Flegr et al. 2003).

Table 3 Differences in testosterone and psychopathological symptoms between Toxoplasma-infected and non-infected women

\begin{tabular}{|c|c|c|c|c|c|c|}
\hline & $\begin{array}{l}\text { Toxoplasma-infected } \\
\text { women }(n=13)\end{array}$ & $\begin{array}{l}\text { Non-infected women } \\
(n=92)\end{array}$ & & & & \\
\hline & \multirow[t]{2}{*}{ Mean $(S D)$} & \multirow[t]{2}{*}{ Mean $(S D)$} & \multirow[t]{2}{*}{$p$} & \multirow[t]{2}{*}{ Hedges' $g$} & \multicolumn{2}{|c|}{$\begin{array}{l}\text { 95\% CI for } \\
\text { Hedges' } g\end{array}$} \\
\hline & & & & & Lower & Upper \\
\hline Testosterone & $0.63(0.37)$ & $1.18(1.69)$ & 0.490 & -0.34 & -0.92 & 0.23 \\
\hline Somatization & $1.07(0.71)$ & $0.97(0.66)$ & 0.596 & 0.14 & -0.43 & 0.73 \\
\hline Obsessive-Compulsive & $1.34(0.89)$ & $1.41(0.89)$ & 0.796 & -0.07 & -0.65 & 0.50 \\
\hline Interpersonal Sensitivity & $1.18(1.14)$ & $1.07(0.83)$ & 0.996 & 0.12 & -0.45 & 0.70 \\
\hline Depression & $1.34(1.00)$ & $1.26(0.91)$ & 0.942 & 0.05 & -0.52 & 0.63 \\
\hline Anxiety & $1.13(0.85)$ & $0.98(0.72)$ & 0.637 & 0.20 & -0.37 & 0.78 \\
\hline Hostility & $0.82(0.75)$ & $0.75(0.77)$ & 0.807 & 0.09 & -0.48 & 0.67 \\
\hline Phobic Anxiety & $0.61(0.44)$ & $0.61(0.69)$ & 0.470 & 0.00 & -0.58 & 0.58 \\
\hline Paranoid Ideation & $1.08(0.90)$ & $0.91(0.79)$ & 0.516 & 0.21 & -0.37 & 0.79 \\
\hline Psychoticism & $0.71(0.68)$ & $0.69(0.65)$ & 0.834 & 0.03 & -0.55 & 0.61 \\
\hline
\end{tabular}


Even though it is possible that $T$. gondii infection and testosterone changes might be mutually influenced, it is not possible to experimentally test whether $T$. gondii infection changes testosterone levels, personality, behavior, and/or psychopathological symptoms in humans, or whether subjects with higher testosterone levels and different personality and behavioral traits vary in the probability of $T$. gondii infection (Kaňková et al. 2011). However, animal studies have shown, that male and female mice that have been experimentally infected with $T$. gondii experience changes in their testosterone levels (Kaňková et al. 2011) or in their dopaminergic neuromodulatory system (Skallová et al. 2006) after infection, suggesting that the direction of the effect is T. gondii infection producing changes in the neuroendocrine system (and therefore in personality, behavior, and psychopathological symptoms), rather than the other way around.

The psychopathological symptom dimension called Interpersonal Sensitivity has been related to the undue and exaggerated sensitivity to rejection (Boyce and Parker 1989). Behaviors and emotions of others often lead to a preoccupation with social relationships, increased sensitivity to criticism, and modifications in behavior to meet others' expectations (Boyce and Parker 1989). This involves a person's ability to correctly observe and interpret their environment and provide appropriate social and emotional responses (Wedgeworth et al. 2017). Previous literature has shown that Interpersonal Sensitivity is associated with poor psychological functioning, and it has been identified as an underlying trait in anxiety disorder (Urbán et al. 2014). Likewise, increased Interpersonal Sensitivity is correlated with low self-esteem, leading to poor social relationships (McCabe et al. 1999). Thus, Interpersonal Sensitivity may be a risk factor for major depression (Liu et al. 2014). We found small but statistically nonsignificant differences in depression and anxiety symptoms among the Toxoplasmainfected men relative to non-infected men (see Table 2), in line with previous observations that latent toxoplasmosis can be related to these traits (see Hsu et al. 2014 for a review).

It is noteworthy that Psychoticism has been associated with psychosis proneness as well as delusions, hallucinations, and other psychotic symptoms (e.g., Spauwen et al. 2006; LeBoutillier et al. 2016), traits commonly associated with impaired testosterone levels (Lodha and Karia 2019). Thus, chronically altered testosterone feedback regulation associated with latent Toxoplasma infection may also be a risk factor for the development of several mental disorders (e.g., schizophrenia and bipolar disorder), probably because of dysregulation of the testosterone feedback axis regulation and its effect on other neurotransmission systems (e.g., dopamine and serotonin systems). In fact, it has been suggested that testosterone may influence glutamatergic, dopaminergic, and GABAergic neurotransmission systems that are closely related to the physiopathology of schizophrenia and other psychiatric disorders (Melcangi et al. 2011).

In this regard, previous literature has hypothesized that higher testosterone levels and the development of mental disorders could be an accidental by-product of chronic T. gondii infection (e.g., Flegr 2007; Brüne 2019). However, it seems that many symptoms associated with psychopathology could represent transmission-related benefits for T. gondii (Brüne 2019; Del Giudice 2019). For example, T. gondii infection blocks the innate aversion of rats for cat urine, increasing the likelihood of a cat predating a rat (Berdoy et al. 2000). According to the "behavioral manipulation hypothesis," T. gondii manipulates the behavior of intermediate hosts to increase its 
own transmission efficiency to its definitive host, a Felidae member (e.g., Del Giudice 2019). In fact, Toxoplasma-infected chimpanzees (Pan Troglodytes troglodytes) lose their innate aversion towards the urine of leopards (Panthera pardus) (Poirotte et al. 2016) and that Toxoplasma-infected men are more attracted to cat odor in comparison to non-infected men (Flegr et al. 2011). Even though humans are no longer common prey of big felines, it is possible that in the past, $T$. gondii manipulated hominid behavior, probably making them easier targets for big cats (Webster 2001; Flegr 2013). This hypothesis could explain why we found effects of T. gondii on psychopathological symptoms and testosterone levels only in men but not in women. ${ }^{1}$ According to anthropological evidence (e.g., Frayer 1980; Silverman et al. 2007), human males were involved in hunting activities more than females, probably putting males at greater risk of being eaten by big felines. This risk may have been even higher if infected men were isolated from the group due to the expression of psychopathological symptoms, which ultimately benefited $T$. gondii by reaching its definitive host.

Another evolutionary explanation for the increased testosterone levels of Toxoplas$m a$-infected men is that $T$. gondii can be sexually transmitted in several mammals, including humans (Arantes et al. 2009; Dass et al. 2011; Hlaváčová et al. 2020). In line with this hypothesis, the increased testosterone levels of Toxoplasma-infected men can affect not only the acquisition of sexual partners through more active mate-seeking and sexual behavior, but also increased attractiveness of the host-all of which would facilitate the spread of $T$. gondii to new hosts. In support of this hypothesis, it has been observed that Toxoplasma-infected male rodents have higher testosterone levels and are more attractive to females (Dass et al. 2011; Kaňková et al. 2011). Evidence also suggests a similar effect in infected men. For example, men who have physical traits associated with higher testosterone levels are more attractive to women, especially when women are in the fertile phase of the menstrual cycle (e.g., Roney et al. 2011; Rantala et al. 2012). Likewise, men who have higher testosterone levels report higher mating success (Peters et al. 2008) and higher number of sexual partners (van Anders et al. 2007). In fact, according to the multidimensional model of the fast-slow life history continuum (Del Giudice 2014, 2017), the elevated testosterone levels in combination with higher Psychoticism and Interpersonal Sensitivity could be interpreted to suggest that Toxoplasma-infection triggers the "seductive/creative" phenotype that may be associated with higher mating success (Del Giudice 2019). Thus, the higher testosterone levels observed in Toxoplasma-infected men could be seen as an adaptation of $T$. gondii to successfully increase its spread (Del Giudice 2017, 2019).

At the same time, the null effect of $T$. gondii infection on testosterone levels in women could be associated with the maintenance of their femininity and attractiveness, so that $T$. gondii would benefit from being sexually transmitted to women and then being vertically transmitted to children. In fact, there is also evidence suggesting that Toxoplasma-infected women have more sons than daughters (Kaňková et al. 2007). This phenomenon has been explained as the result of the immunosuppression exerted

\footnotetext{
${ }^{1}$ Other explanations for the null finding in women include a floor effect caused by the lower range of testosterone levels in women relative to men, which would make it harder to detect significant Toxoplasmainduced differences in women than in men. Another possibility is that our study did not have adequate statistical power to detect an effect because of the small number of women who were infected with $T$. gondii. We encourage future studies on larger samples of infected men and women to enable adequate statistical power for detecting even small effect sizes.
} 
by $T$. gondii but it could also be explained by the higher number of sexual partners that men reportedly get during their lifetime (Mitchell et al. 2019; Borráz-León and Rantala 2021), which would benefit the parasite on a long-term scale.

In general, these evolutionary explanations can be complementary and useful in explaining the effect of $T$. gondii on endocrine changes and the development of psychopathological symptoms, probably as a direct or indirect effect of the manipulation exerted by this parasite either to isolate infected individuals from the group and reach its definitive host (as a remnant effect of its strategy on savannah hominids), or to increase the mating success of infected men to spread the parasite to women and then to their offspring. Further studies are needed to properly test these hypotheses.

\section{Conclusion}

The ability of parasites to hijack the nervous system of host organisms in a way that enhances parasite fitness whilst compromising host fitness is a topic of significant interest in evolutionary biology (Dawkins 1982; Geffre et al. 2017; Del Giudice 2019). The importance of this study lies in providing an evolutionarily informed analysis on the endocrine mechanisms by which $T$. gondii influences the nervous system of its human hosts, including the development of psychopathological symptoms. From an evolutionary point of view, such psychopathological symptoms and their behavioral sequelae can comprise direct or indirect manipulative effects of a parasite on its intermediate hosts, which may ultimately cause a fitness detriment to the host organism (Del Giudice 2019). In the aggregate, this research opens new avenues for including parasite-host interactions, parasite-induced endocrinological changes, and evolutionary science as important yet understudied factors in the science of mental disorders, facilitating translational psychiatry in developing a scientifically more accurate method of psychopathological diagnosis and potential treatment.

Acknowledgements JIBL and JCG thank the facilities and support of ENES-Morelia, UNAM. The authors are grateful to the volunteers who participated in this research. Especially to the students of the Bachelor in Ecology.

Funding Open Access funding provided by University of Turku (UTU) including Turku University Central Hospital. This research was funded in part by the Consejo Nacional de Ciencia y Tecnología CONACYT through a 2019 postdoctoral fellowship grant to JIBL. JCG was supported by UNAM-PAPIIT grant (IN225120). IK and TK were supported by grants by the Latvian Council of Science (lzp-2018/1-0393) and Estonian Research Council (PUT1223).

\section{Compliance with Ethical Standards}

Conflict of Interest The authors declare no conflict of interest.

Open Access This article is licensed under a Creative Commons Attribution 4.0 International License, which permits use, sharing, adaptation, distribution and reproduction in any medium or format, as long as you give appropriate credit to the original author(s) and the source, provide a link to the Creative Commons licence, and indicate if changes were made. The images or other third party material in this article are included in the article's Creative Commons licence, unless indicated otherwise in a credit line to the material. If material is not included in the article's Creative Commons licence and your intended use is not permitted by statutory 
regulation or exceeds the permitted use, you will need to obtain permission directly from the copyright holder. To view a copy of this licence, visit http://creativecommons.org/licenses/by/4.0/.

\section{References}

Arantes, T. P., Lopes, W. D. Z., Ferreira, R. M., Pieroni, J. S. P., Pinto, V. M., Sakamoto, C. A., \& da Costa, A. J. (2009). Toxoplasma gondii: Evidence for the transmission by semen in dogs. Experimental Parasitology, 123, 190-194. https://doi.org/10.1016/j.exppara.2009.07.003.

Barch, D. M., Shirtcliff, E. A., Elsayed, N. M., Whalen, D., Gilbert, K., Vogel, A. C., Tillman, R., \& Luby, J. L. (2020). Testosterone and hippocampal trajectories mediate the relationship of poverty to emotion dysregulation and depression. Proceedings of the National Academy of Sciences, 117, 22015-22023. https://doi.org/10.1073/pnas.2004363117.

Berdoy, M., Webster, J. P., \& Macdonald, D. W. (2000). Fatal attraction in rats infected with Toxoplasma gondii. Proceedings of the Royal Society B: Biological Sciences, 267, 1591-1594. https://doi.org/10. 1098/rspb.2000.1182.

Booth, A., Johnson, D. R., \& Granger, D. A. (1999). Testosterone and men's depression: the role of social behavior. Journal of Health and Social Behavior, 40, 130-140.

Borráz-León, J. I., \& Rantala, M. J. (2021). Does the Dark Triad predict self-perceived attractiveness, mate value, and number of sexual partners both in men and women? Personality and Individual Differences, 168, 110341. https://doi.org/10.1016/j.paid.2020.110341.

Borráz-León, J. I., Cerda-Molina, A. L., Choi, D., \& Mayagoitia-Novales, L. (2018). Testosterone and intrasexual competition in men: Is there any relationship with digit ratio (2D:4D)? Acta Ethologica, 21, 137-140. https://doi.org/10.1007/s10211-018-0284-9.

Boyce, P., \& Parker, G. (1989). Development of a scale to measure interpersonal sensitivity. Australian \& New Zealand Journal of Psychiatry, 23, 341-351. https://doi.org/10.3109/00048678909068294.

Brüne, M. (2019). Latent toxoplasmosis: host-parasite interaction and psychopathology. Evolution, Medicine, and Public Health, 2019, 212-213. https://doi.org/10.1093/emph/eoz032.

Cicchetti, D. (2016). Socioemotional, personality, and biological development: Illustrations from a multilevel developmental psychopathology perspective on child maltreatment. Annual Review of Psychology, 67, 187-211. https://doi.org/10.1146/annurev-psych-122414-033259.

Cobey, K. D., Nicholls, M., Leongómez, J. D., \& Roberts, S. C. (2015). Self-reported dominance in women: Associations with hormonal contraceptive use, relationship status, and testosterone. Adaptive Human Behavior and Physiology, 1, 449-459. https://doi.org/10.1007/s40750-015-0022-8.

Cook, T. B., Brenner, L. A., Cloninger, C. R., Langenberg, P., Igbide, A., Giegling, I., Hartmann, A. M., Konte, B., Friedl, M., Brundin, L., Groer, M. W., Can, A., Rujescu, D., \& Postolache, T. T. (2015). "Latent" infection with Toxoplasma gondii: association with trait aggression and impulsivity in healthy adults. Journal of Psychiatric Research, 60, 87-94. https://doi.org/10.1016/j.jpsychires.2014.09.019.

Costa, R. M., Correia, M., \& Oliveira, R. F. (2015). Does personality moderate the link between women's testosterone and relationship status? The role of extraversion and sensation seeking. Personality and Individual Differences, 76, 141-146. https://doi.org/10.1016/j.paid.2014.12.003.

Cruz Fuentes, C. S., López Bello, L., Blas García, C., González Macías, L., \& Chávez, Balderas, R. A. (2005). Datos sobre la validez y confiabilidad de la Symptom Check List 90 (SCL-90) en una muestra de sujetos mexicanos. Salud Mental, 28, 72-81.

Dass, S. A. H., Vasudevan, A., Dutta, D., Soh, L. J. T., Sapolsky, R. M., \& Vyas, A. (2011). Protozoan parasite Toxoplasma gondii manipulates mate choice in rats by enhancing attractiveness on males. PLoS ONE, 6, e27229. https://doi.org/10.1371/journal.pone.0027229.

Dawkins, R. (1982). The extended phenotype: The long reach of the gene. Oxford: Oxford University Press.

Del Giudice, M. (2014). An evolutionary life history framework for psychopathology. Psychological Inquiry, 25, 261-300. https://doi.org/10.1080/1047840X.2014.884918.

Del Giudice, M. (2017). Mating, sexual selection, and the evolution of schizophrenia. World Psychiatry, 16, 141. https://doi.org/10.1002/wps.20409.

Del Giudice, M. (2019). Invisible designers: Brain evolution through the lens of parasite manipulation. The Quarterly Review of Biology, 94, 249-282. https://doi.org/10.1086/705038.

Del Giudice, M. D., \& Ellis, B. J. (2016). Evolutionary foundations of developmental psychopathology. Developmental Psychopathology, 1-58. https://doi.org/10.1002/9781119125556.devpsy201 
Derogatis, L. R., \& Unger, R. (2010). Symptom checklist-90-revised. The Corsini encyclopedia of psychology, 1-2. https://doi.org/10.1002/9780470479216.corpsy0970

Eisenegger, C., Haushofer, J., \& Fehr, E. (2011). The role of testosterone in social interaction. Trends in Cognitive Sciences, 15, 263-271. https://doi.org/10.1016/j.tics.2011.04.008.

Figueira, M. L., \& Ouakinin, S. (2010). Gender-related endocrinological dysfunction and mental disorders. Current Opinion in Psychiatry, 23, 369-372. https://doi.org/10.1097/YCO.0b013e3283399b86.

Flegr, J. (2007). Effects of Toxoplasma on human behavior. Schizophrenia Bulletin, 33, 757-760. https://doi. org/10.1093/schbul/sb1074.

Flegr, J. (2013). How and why Toxoplasma makes us crazy. Trends in Parasitology, 29, 156-163. https://doi. org/10.1016/j.pt.2013.01.007.

Flegr, J., \& Horáček, J. (2019). Negative effects of latent toxoplasmosis on mental health. Frontiers in Psychiatry, 10, 1012. https://doi.org/10.3389/fpsyt.2019.01012.

Flegr, J., Preiss, M., Klose, J., Havlíček, J., Vitáková, M., \& Kodym, P. (2003). Decreased level of psychobiological factor novelty seeking and lower intelligence in men latently infected with the protozoan parasite Toxoplasma gondii Dopamine, a missing link between schizophrenia and toxoplasmosis? Biological Psychology, 63, 253-268. https://doi.org/10.1016/S0301-0511(03)00075-9.

Flegr, J., Lindová, J., \& Kodym, P. (2008). Sex-dependent toxoplasmosis-associated differences in testosterone concentration in humans. Parasitology, 135, 427-431. https://doi.org/10.1017/S0031182007004064.

Flegr, J., Lenochová, P., Hodný, Z., \& Vondrová, M. (2011). Fatal attraction phenomenon in humans-cat odour attractiveness increased for Toxoplasma-infected men while decreased for infected women. PLOS Neglected Tropical Diseases, 5, e1389. https://doi.org/10.1371/journal.pntd.0001389.

Frayer, D. W. (1980). Sexual dimorphism and cultural evolution in the late Pleistocene and Holocene of Europe. Journal of Human Evolution, 95, 399-415. https://doi.org/10.1016/0047-2484(80)90050-0.

Geffre, A. C., Liu, R., Manfredini, F., Beani, L., Kathirithamby, J., Grozinger, C. M., \& Toth, A. L. (2017). Transcriptomics of an extended phenotype: Parasite manipulation of wasp social behaviour shifts expression of caste-related genes. Proceedings of the Royal Society B: Biological Sciences, 284, 20170029. https://doi.org/10.1098/rspb.2017.0029.

Giammanco, M., Tabacchi, G., Giammanco, S., Di Majo, D., \& La Guardia, M. (2005). Testosterone and aggressiveness. Medical Science Monitor, 11. In RA136-RA145.

Hlaváčová, J., Flegr, J., Řežábek, K., Calda, P., \& Kaňková, Š. (2020). Male-to-Female presumed transmission of Toxoplasmosis between sexual partners. American Journal of Epidemiology, Kwaa 198. https:// doi.org/10.1093/aje/kwaa198

Hsu, P. C., Groer, M., \& Beckie, T. (2014). New findings: depression, suicide, and Toxoplasma gondii infection. Journal of the American Association of Nurse Practitioners, 26, 629-637. https://doi.org/10. 1002/2327-6924.12129.

Hull, E. M., Muschamp, J. W., \& Sato, S. (2004). Dopamine and serotonin: influences on male sexual behavior. Physiology and Behavior, 83, 291-307. https://doi.org/10.1016/j.physbeh.2004.08.018.

Kaňková, Š., Šulc, J., Nouzová, K., Fajfrlík, K., Frynta, D., \& Flegr, J. (2007). Women infected with parasite Toxoplasma have more sons. Naturwissenschaften, 94, 122-127. https://doi.org/10.1007/s00114-0060166-2.

Kaňková, Š., Kodym, P., \& Flegr, J. (2011). Direct evidence of Toxoplasma-induced changes in serum testosterone in mice. Experimental Parasitology, 128, 181-183. https://doi.org/10.1016/j.exppara.2011. 03.014.

Khera, M. (2013). Patients with testosterone deficiency syndrome and depression. Archivos Españoles de Urologia, 66, 729-736.

Lara, M. A., Navarrete, L., Nieto, L., \& Le, H. N. (2015). Childhood abuse increases the risk of depressive and anxiety symptoms and history of suicidal behavior in Mexican pregnant women. Brazilian Journal of Psychiatry, 37, 203-210. https://doi.org/10.1590/1516-4446-2014-1479.

LeBoutillier, N., Barry, R., \& Westley, D. (2016). Creativity and the measurement of subclinical psychopathology in the general population: Schizotypy, psychoticism, and hypomania. Psychology of Aesthetics, Creativity, and the Arts, 10, 240-247. https://doi.org/10.1037/aca0000047.

Lim, A., Kumar, V., Dass, S. A. H., \& Vyas, A. (2013). Toxoplasma gondii infection enhances testicular steroidogenesis in rats. Molecular Ecology, 22, 102-110. https://doi.org/10.1111/mec.12042.

Liu, R. T., Kraines, M. A., Massing-Schaffer, M., \& Alloy, L. B. (2014). Rejection sensitivity and depression mediation by stress generation. Psychiatry: Interpersonal and Biological Processes, 77, 86-97. https:// doi.org/10.1521/psyc.2014.77.1.86.

Lodha, P., \& Karia, S. (2019). Testosterone and schizophrenia: A clinical review. Annals of Indian Psychiatry, 3, 92-96. https://doi.org/10.4103/aip.aip_54_19. 
Luoto, S. (2020). Sex differences in people and things orientation are reflected in sex differences in academic publishing. Journal of Informetrics, 14, 101021. https://doi.org/10.1016/j.joi.2020.101021.

Luoto, S., Krams, I., \& Rantala, M. J. (2019). A life history approach to the female sexual orientation spectrum: Evolution, development, causal mechanisms, and health. Archives of Sexual Behavior, 48, 1273-1308. https://doi.org/10.1007/s10508-018-1261-0.

Maddux, J. E., \& Winstead, B. A. (2015). Psychopathology: Foundations for a contemporary understanding. Routledge. https://doi.org/10.4324/9781315778945

Manning, N. (2019). Sociology, biology and mechanisms in urban mental health. Social Theory \& Health, 17 , 1-22. https://doi.org/10.1057/s41285-018-00085-7.

Marcinkowska, U. M., Helle, S., Jones, B. C., \& Jasienska, G. (2019). Does testosterone predict women's preference for facial masculinity? PloS ONE, 14, e0210636. https://doi.org/10.1371/journal.pone. 0210636.

McCabe, R. E., Blankstein, K. R., \& Mills, J. S. (1999). Interpersonal sensitivity and social problem-solving: Relations with academic and social self-esteem, depressive symptoms, and academic performance. Cognitive Therapy and Research, 23, 587-604. https://doi.org/10.1023/A:1018732707476.

Melcangi, R. C., Panzica, G., \& Garcia-Segura, L. M. (2011). Neuroactive steroids: focus on human brain. Neuroscience, 191(1-5). https://doi.org/10.1016/j.neuroscience.2011.06.024.

Mitchell, K. R., Mercer, C. H., Prah, P., Clifton, S., Tanton, C., Wellings, K., \& Copas, A. (2019). Why do men report more opposite-sex sexual partners than women? Analysis of the gender discrepancy in a British national probability survey. The Journal of Sex Research, 56, 1-8. https://doi.org/10.1080/ 00224499.2018.1481193.

Montoya, J., \& Liesenfeld, O. (2004). Toxoplasmosis. Lancet, 363, 1965-1976. https://doi.org/10.1016/ S0140-6736(04)16412-X.

Peters, M., Simmons, L. W., \& Rhodes, G. (2008). Testosterone is associated with mating success but not attractiveness or masculinity in human males. Animal Behaviour, 76, 297-303. https://doi.org/10.1016/j. anbehav.2008.02.008.

Poirotte, C., Kappeler, P. M., Ngoubangoye, B., Bourgeois, S., Moussodji, M., \& Charpentier, M. J. (2016). Morbid attraction to leopard urine in Toxoplasma-infected chimpanzees. Current Biology, 26, R98-R99. https://doi.org/10.1016/j.cub.2015.12.020.

Rantala, M. J., Moore, F. R., Skrinda, I., Krama, T., Kivleniece, I., Kecko, S., \& Krams, I. (2012). Evidence for the stress-linked immunocompetence handicap hypothesis in humans. Nature Communications, 3, 15. https://doi.org/10.1038/ncomms1696.

Rantala, M. J., Luoto, S., Krams, I., \& Karlsson, H. (2018). Depression subtyping base on evolutionary psychiatry: Proximate mechanisms and ultimate functions. Brain, Behavior, and Immunity, 69, 603-617. https://doi.org/10.1016/j.bbi.2017.10.012.

Rantala, M. J., Luoto, S., Krama, T., \& Krams, I. (2019). Eating disorders: An evolutionary psychoneuroimmunological approach. Frontiers in Psychology, 10, 2200. https://doi.org/10.3389/fpsyg. 2019.02200 .

Richards, G., Klimek, M., Jasienska, G., \& Marcinkowska, U. M. (2018). Digit ratio (2D:4D) and circulating testosterone, oestradiol, progesterone levels across the menstrual cycle. Early Human Development, 117, 68-73. https://doi.org/10.1016/j.earlhumdev.2017.12.006.

Roberts, A., Hedman, K., Luyasu, V., Zufferey, J., Bessières, M. H., Blatz, R. M., Candolfi, E., Decoster, A., Enders, G., Gross, U., Guy, E., Hayde, M., Ho-Yen, D., Johnson, J., Lécolier, B., Naessens, A., Pelloux, H., Thulliez, P., \& Petersen, E. (2001). Multicenter evaluation of strategies for serodiagnosis of primary infection with Toxoplasma gondii. European Journal of Clinical Microbiology and Infectious Diseases, 20, 467-474. https://doi.org/10.1007/PL00011289.

Roney, J. R., Simmons, Z. L., \& Gray, P. B. (2011). Changes in estradiol predict within-women shifts in attraction to facial cues of men's testosterone. Psychoneuroendocrinology, 36, 742-749. https://doi.org/ 10.1016/j.psyneuen.2010.10.010.

Silverman, I., Choi, J., \& Peters, M. (2007). The hunter-gatherer theory of sex differences in spatial abilities: Data from 40 countries. Archives of Sexual Behavior, 36, 261-268. https://doi.org/10.1007/s10508-0069168-6.

Skallová, A., Kodym, P., Frynta, D., \& Flegr, J. (2006). The role of dopamine in Toxoplasma-induced behavioural alterations in mice: an ethological and ethnopharmacological study. Parasitology, 133, 525535. https://doi.org/10.1017/S0031182006000886.

Spauwen, J., Krabbendam, L., Lieb, R., Wittchen, H. U., \& Van Os, J. (2006). Impact of psychological trauma on the development of psychotic symptoms: relationship with psychosis proneness. The British Journal of Psychiatry, 188, 527-533. https://doi.org/10.1192/bjp.bp.105.011346. 
Szczypka, M. S., Zhou, Q. Y., \& Palmiter, R. D. (1998). Dopamine-stimulated sexual behavior is testosterone dependent mice. Behavioral Neuroscience, 112, 1229-1235. https://doi.org/10.1037/0735-7044.112.5. 1229.

Torrey, E. F., \& Yolken, R. H. (2019). Schizophrenia as a pseudogenetic disease: A call for more geneenvironmental studies. Psychiatry Research, 278, 146-150. https://doi.org/10.1016/j.psychres.2019.06. 006.

Torrey, E. F., Bartko, J. J., Lun, Z. R., \& Yolken, R. H. (2006). Antibodies to Toxoplasma gondii in patients with schizophrenia: a meta-analysis. Schizophrenia Bulletin, 33, 729-736. https://doi.org/10.1093/schbul/ sb1050.

Urbán, R., Kun, B., Farkas, J., Paksi, B., Kökönyei, G., Unoka, Z., Felvinczi, K., Oláh, A., \& Demetrovics, Z. (2014). Bifactor structural model of symptom checklists: SCL-90-R and Brief Symptom Inventory (BSI) in a non-clinical community simple. Psychiatry Research, 216, 146-154. https://doi.org/10.1016/j. psychres.2014.01.027.

van Anders, S. M., Hamilton, L. D., \& Watson, N. V. (2007). Multiple partners are associated with higher testosterone in North American men and women. Hormones and Behavior, 51, 454 459. https://doi.org/ 10.1016/j.yhbeh.2007.01.002.

Webster, J. P. (2001). Rats, cats, people and parasites: the impact of latent toxoplasmosis on behaviour. Microbes and Infection, 3, 1037-1045. https://doi.org/10.1016/S1286-4579(01)01459-9.

Wedgeworth, M., LaRocca, M. A., Chaplin, W. F., \& Scogin, F. (2017). The role of interpersonal sensitivity, social support, and quality of life in rural older adults. Geriatric Nursing, 38, 22-26. https://doi.org/10. 1016/j.gerinurse.2016.07.001.

Welling, L. L., Jones, B. C., DeBruine, L. M., Conway, C. A., Smith, M. L., Little, A. C., \& Al-Dujaili, E. A. (2007). Raised salivary testosterone in women is associated with increased attraction to masculine faces. Hormones and Behavior, 52, 156-161. https://doi.org/10.1016/j.yhbeh.2007.01.010.

Zouei, N., Shojaee, S., Mohebali, M., \& Keshavarz, H. (2018). The association of latent toxoplasmosis and level of serum testosterone in humans. BMC Research Notes, 11, 365. https://doi.org/10.1186/s13104018-3468-5.

Publisher's Note Springer Nature remains neutral with regard to jurisdictional claims in published maps and institutional affiliations.

\section{Affiliations}

\section{Javier I. Borráz-León ${ }^{1,2,3}$ - Markus J. Rantala ${ }^{1}$ - Severi Luoto ${ }^{4,5} \cdot$ Indrikis Krams $^{6,7,8}$ • Jorge Contreras-Garduño ${ }^{3}$ - Ana Lilia Cerda-Molina ${ }^{2} \cdot$ Tatjana Krama $^{9}$}

Department of Biology, University of Turku, Turku, Finland

2 Department of Ethology, National Institute of Psychiatry "Ramón de la Fuente Muñiz", Mexico City, Mexico

3 Evolutionary Ecology Lab, ENES, National Autonomous University of Mexico, Morelia, Mexico

4 English, Drama and Writing Studies, University of Auckland, Auckland, New Zealand

5 School of Psychology, University of Auckland, Auckland, New Zealand

6 Institute of Systematic Biology, Daugavpils University, Daugavpils, Latvia

7 Institute of Ecology and Earth Sciences, University of Tartu, Tartu, Estonia

8 Department of Psychology, University of Tennessee, Knoxville, USA

9 Department of Biotechnology, Daugavpils University, Daugavpils, Latvia 